\title{
ANALISIS BIAYA DAN FAKTOR PRODUKSI USAHATANI BUNGA POTONG KRISAN (Chrysanthemum indicum L.) STUDI KASUS DI DESA WONOSARI KECAMATAN TUTUR KABUPATEN PASURUAN
}

\section{COST ANALYSIS AND PRODUCTION FACTOR OF CHRYSANTHEMUM CUTTING FLOWER (Chrysanthemum indicum L.) CASE STUDY IN WONOSARI VILLAGE, TUTUR DISTRICT OF PASURUAN DISTRICT}

\author{
Aprilinda Soi ${ }^{1)}$, Evi Nurifah Julitasari ${ }^{2)}$, dan Darmadji ${ }^{2)}$ \\ ${ }^{1)}$ Alumni Fakultas Pertanian Universitas Widyagama Malang \\ ${ }^{2)}$ Dosen Fakultas Pertanian Universitas Widyagama Malang \\ Email: uwg.stefaniaprilinda@gmail.com
}

\begin{abstract}
ABSTRAK
Tanaman bunga potong krisan ( Chrysantemum indicum L.) merupakan salah satu jenis tanaman hias yang bernilai ekonomi, yang menjadi sumber pendapatan petani di Desa Wonosari Kecamatan Tutur Kabupaten Pasuruan. Penelitian ini bertujuan untuk mengetahui: (1) Biaya produksi dan pendapatan dalam usahatani bunga potong krisan, (2) Faktor produksi yang mempengaruhi usahatani bunga potong krisan, (3) Tingkat efisiensi usahatani bunga potong krisan. Sampel penelitian adalah petani bunga potong krisan di Desa Wonosari Kecamatan Tutur Kabupaten Pasuruan. Metode penentuan sampel dilakukan secara random. Metode pengambilan data melalui wawancara langsung berdasarkan kuisioner yang telah disiapkan. Metode analisis data menggunakan model regresi linear berganda dan analisis R/C ratio dan $\mathrm{B} / \mathrm{C}$ ratio. Hasil analisis menunjukan bahwa: (1) biaya yang dikeluarkan oleh petani bunga potong krisan sebesar Rp18.220.712/ha/musim dengan keuntungan sebesar Rp 43.129.288/ha/musim; (2) Secara bersama-sama faktor luas lahan, tenaga kerja, bibit, pupuk kandang dan pestisida berpengaruh terhadap produksi bunga potong krisan, (3) Secara parsial luas lahan, bibit dan pupuk kandang berpengaruh sangat nyata terhadap produksi bunga potong krisan, sedangkan variabel tenaga kerja dan pestisida tidak berpengaruh (4) Biaya produksi R/C ratio 3.37, sementara nilai $\mathrm{B} / \mathrm{C}$ ratio 2,37 .
\end{abstract}

Kata kunci: Bunga potong krisan, biaya produksi, produksi, $\mathrm{R} / \mathrm{C}$ ratio, $\mathrm{B} / \mathrm{C}$ ratio, faktor produksi

\begin{abstract}
Chrysanthemum plant (Chrysanthemum indicum L.) is one of the most valuable ornamental plants which become a source of income for farmers in the village of Wonosari, Tutur district of Pasuruan. This study aims are to know: (1) The production cost and income in cut flower chrysanthemum farming, (2) Production factors which affect the cut flower chrysanthemum farming, (3) The efficiency level of cut flower chrysanthemum farming. The sample of this research is cut chrysanthemum farmer in Wonosari village, Tutur district of Pasuruan. The method of determining the sample is done randomly. Method of collecting data through direct interview is based on prepared questionnaire. Methods of data analysis used is multiple linear regression model, and $R / C$ ratio analysis and $B / C$ ratio. The results
\end{abstract}


of the analysis show that: (1) the cost incurred by the farmers of chrysanthemum flower is $R p$ 18.220.712/ha/season and the profit is $R p$ 43.129.288/ha/season. (2) Simultaneously, land area, labor, seed, manure and pesticide affect on chrysanthemum production, (3) partially, land area, seed and manure have a very significant effect on chrysanthemum cut flower production, while the variables of labor and pesticide have no effect (4) production cost $R / C$ ratio is 3.37 , while the value of $B / C$ ratio is 2.37 .

Keywords: Chrysanthemum cut flower, production cost, production, $R / C$ ratio, $B / C$ ratio, production factor

\section{PENDAHULUAN}

Tanaman hias bunga krisan merupakan bunga potong yang penting di dunia. Prospek budidaya bunga krisan sebagai bunga potong sangat cerah, karena pasar potensial yang dapat berdaya serap tinggi sudah ada.Tanaman bunga krisan (Chrysantemum indicum L.) merupakan salah satu jenis tanaman hias yang bernilai ekonomi, tidak hanya sebagai sumber kesehatan, namun juga sebagai sumber pendapatan bagi sebagian besar petani diderah sentr produksinya. Selain itu bunga krisan juga memiliki jenis yang cukup banyak (Andiani, 2013).

Sentra produksi bunga krisan terdapat di kecamatan Tutur Kabupaten Pasuruan, Kecamatan Poncokusumo, Kabupaten Malang, kota Batu dan mulai berkembang di kecamatan Pacet, Kabupaten Mojo- kerto. Meningkatnya permintaan pasar terhadap bunga krisan, memberikan dampak yang positif yaitu terbukanya peluang untuk mengekspor dengan harga yang mampu bersaing. Keadaan inilah yang nampak pada beberapa tahun belakangan ini makin meluasnya usaha membudidayakan bunga krisan, baik dalam skala kecil maupun skala besar.

Suatu usaha harus mampu mengelola usahanya secara cepat, mengingat masih terbukanya peluang pasar untuk bunga potong krisan dan perkembangan dunia usaha saat ini yang mengalami kemajuan cukup pesat namun tingkat persaingan cukup ketat, dan banyak bermunculan berbagi macam jenis usaha baru yang sejenis. Dengan demikin diperlukan suatu analisis usaha, oleh karena itu penulis tertarik untuk meneliti dan menganalisis 
biaya dan pendapatan usahatani bunga potong krisan dengan mengambil lokasi penelitian di Desa Tutur, Kecamatan Tutur, Kabupaten Pasuruan.

Penelitian ini dilakukan untuk mengetahui: (a) Biaya produksi dan pendapatan usahatani bunga potong krisan, (b) Faktor apa yang mempengaruhi produksi usahatani bunga potong krisan, dan (c) Tingkat efisiensi usahatani bunga potong krisan.

\section{METODE PENELITIAN}

\section{Lokasi Penelitian}

Penelitian ini dilakukan menggunakan pendekatan kualitatif, dilakukan di Desa Tutur, Kecamatan Tutur, Kabupaten Pasuruan. Penentuan lokasi ditentukan secara sengaja atau purposive, dengan pertimbangan bahwa Desa Wonosari merupakan salah satu desa sentral produksi Bunga Potong Krisan di Kecamatan Tutur, Kabupaten Malang.

\section{Sampel Petani}

Petani sebagai sampel adalah petani yang mengusahakan bunga potong krisan. Pemilihan sampel dilakukan secara random dengan pertimbangan terhadap karakteristik sosial, ekonomi, budaya dan pendidikan responden adalah homogen.

\section{Metode Pengambilan Data}

Data yang digunakan dalam penelitian ini adalah data primer, diperoleh dengan cara wawancara secara langsung dengan petani bunga krisan potong, menggunakan kuesioner yang telah disiapkan. Data yang dimaksud meliputi: (a) produksi, (b) input produksi, (c) harga produksi, (d) harga input produksi, (e) keadaan sosial petani (umur, pendidikan, pengalaman), (f) dan lainnya.

Selain data primer juga data sekunder, yakni sebagai pendukung data primer yang dipergunakan sebagai satuan analisis.

\section{Metode Analisis Data}

\section{Analisis Efisiensi}

Untuk analisis efisiensi usahatani bunga potong krisan digunakan metode sebagai berikut :

$\mathrm{TC}=$ Total Cost, $\mathrm{TVC}=$ Total Variable Cost, TFC $=$ Total Fixed Cost.

$\mathrm{TC}=\mathrm{TVC}+\mathrm{TFC}$ 
TR= Py x Y, (TR = Total Revenue $)$

Py $=$ Harga Produksi, $Y=$ Produksi

$\mathrm{I}=\mathrm{TR}-\mathrm{TC},(\mathrm{I}=$ Pendapatan, $\mathrm{TR}=$

Total Revenue, $\mathrm{TC}=$ Total Cost $)$.

Efisien, digunakan analisis $\mathrm{R} / \mathrm{C}$ ratio dan $\mathrm{B} / \mathrm{C}$

\section{Analisis Faktor Produksi}

Untuk mengetahui faktor faktor yang mempengaruhi produksi usahatani bunga potong krisan menggunakan analisis Fungsi Produksi Cobb Douglas, dengan formula sebagai berikut :

$\operatorname{Ln} Y=\operatorname{Ln} b_{0}+b_{1} \operatorname{LnX} X_{1}+b_{2} \operatorname{LnX}_{2}+$

$b_{3} \operatorname{LnX}_{3}+b_{4} \operatorname{Ln} X_{4}+b_{5} \operatorname{LnX} X_{5}+e i$

Keterangan :

$\mathrm{Y}=$ Produksi

Ln $\mathrm{b}_{0}=$ Konstanta

$\mathrm{X}_{1}=$ Luas lahan (ha)

$\mathrm{X}_{2}=$ Tenaga kerja (hkp)

$\mathrm{X}_{3}=$ Bibit (batang)

$\mathrm{X}_{4}=$ Pupuk kandang $(\mathrm{kg})$
$\mathrm{X}_{5}=$ Pestisida (liter)

$\mathrm{ei}=$ Residual

$b_{1}, b_{2}, \ldots b_{5}=$ koefisien regresi

(parameter) yang harus diuji.

Dengan program SPSS dilakukan analisis untuk menemukan model produksi usahatani bunga potong krisan. Dengan hasil uji koefisien regresi (parameter) dapat diketahui pengaruh masing-masing variabel independen terhadap produksi.

\section{HASIL DAN PEMBAHASAN}

\section{Analisis Efisiensi Usaha}

Hasil penelitian analisis biaya dan pendapatan usahatani bunga potong krisan terdiri dari :

\section{Biaya tetap $($ Fixed Cost $=$ FC $)$}

Hasil analisis biaya tetap usahatani bunga potong krisan adalah sebagai berikut (Tabel 1):

Tabel 1. Biaya Tetap Usahatani Bunga Potong Krisan di Desa Wonosari, Kecamatan Tutur, Kabupaten Pasuruan

\begin{tabular}{llrc}
\hline No & Jenis Biaya & Total $(\mathbf{R p})$ & Persentase $(\boldsymbol{\%})$ \\
\hline 1 & Pajak & $75.444,27$ & 62,3 \\
2 & Penyusutan & $45.694,43$ & 37,7 \\
\hline \multirow{2}{*}{ Total } & & $\mathbf{1 2 1 . 1 3 8 , 7 0}$ & $\mathbf{1 0 0}$ \\
\hline
\end{tabular}

Sumber : Data primer (2016)

Berdasarkan Tabel 1 nampak bahwa biaya tetap usahatani bunga potong krisan adalah Rp 75.444,27 + Rp 45.694,43 = Rp 121.138,70. 
Biaya tidak tetap (Variable Cost)

Biaya tidak tetap adalah biaya yang dikeluarkan petani yang besar kecilnya tergantung dari besar atau kecilnya produksi yang dihasilkan. Biaya ini meliput biaya untuk sarana produksi bunga potong krisan. Biaya variabel meliputi biaya untuk pembelian bibit, pupuk, pestisida, kapur pertanian, tenaga kerja, biaya pengolahan lahan dan biaya lainnya. Untuk lebih jelasnya dapat dilihat pada Tabel 2. berikut ini.

Tabel 2. Komponen Rata-rata Biaya Variabel Usahatani Bunga Potong Krisan

\begin{tabular}{lrr}
\hline & \multicolumn{2}{c}{ Biaya Variabel } \\
\cline { 2 - 3 } Keterangan & Rp (Rupiah) & Prosentase (\%) \\
\hline Bibit & 4.090 .000 & 22,60 \\
Pupuk Kandang & 5.755 & 0,032 \\
Pupuk Urea & 1.401 .650 & 7,744 \\
Pupuk SP36 & 253667 & 1,402 \\
Pupuk Za & 1420417 & 7,85 \\
Pestisida & 514.267 & 2,84 \\
Kapur Pertanian & 123.817 & 0,68 \\
Tenaga Kerja & 10.290 .000 & 56,85 \\
\hline Total & $\mathbf{1 8 . 0 9 9 . 5 7 3}$ & $\mathbf{1 0 0}$ \\
\hline Sumber: Data Primer Diolah $(2016)$ & &
\end{tabular}

Bedasarkan pada Tabel 2 dapat

diketahui bahwa jumlah biaya ratarata produksi usahatani bunga potong krisan mencapai Rp 18.099.573/ha/musim. Untuk komponen biaya variabel yang terbesar adalah tenaga kerja.

\section{Pendapatan Usahatani Bunga Potong Krisan}

Hasil analisis pendapatan usahatani bunga potong krisan dapat dilihat dari tingkat rata-rata hasil produksi, harga jual, penerimaan, biaya dan pendapatan usahatani bunga potong krisan, Tabel 3 . 
Tabel 3. Rata-Rata Biaya, Penerimaan, Hasil Produksi, Harga Jual dan Pendapatan, Usahatani Bunga Potong Krisan di Desa Wonosari, Kecamatan Tutur, Kabupaten Pasuruan

\begin{tabular}{ccc}
\hline No & Keterangan(Per Petani) & Jumlah(Rp) \\
\hline 1 & Total Biaya & 18.220 .712 \\
& a. Biaya Tetap & 18.099 .573 \\
& b. Biaya & $121.138,70$ \\
2 & Total Penerimaan & 61.350 .000 \\
& a. Hasil Produksi & 61.350 \\
3 & b. Harga Jual & 1000 \\
& Pendapatan & 43.129 .288
\end{tabular}

Sumber: Data Primer Diolah (2016)

Berdasarkan Tabel 1, Tabel 2 dan Tabel 3 maka dapat dihitung angka kelayakan usaha dan angka efisiensi usaha, sebagai berikut :

a. $\quad$ Biaya tetap $=\operatorname{Rp} 121.138,70$

b. Biaya variabel = $\mathrm{Rp}$ 18.099.573,0

c. Total Penerimaan $=\mathrm{Rp}$ 61.350.000; /ha/musim

d. $\quad$ Total biaya $=\operatorname{Rp~121.138,70+~}$ $\mathrm{Rp} \quad 18.099 .573,0=\mathrm{Rp}$ $18.220 .711,0$

e. $\quad$ Pendapatan $=\operatorname{Rp} 43.129 .288,0$

Dari hasil perhitungan total biaya, total penerimaan dan pendapatan usahatani bunga potong krisan di atas maka angka kelayakan usaha dan efisiensi usahatani bunga potong krisan adalah sebagai berikut :

a. Kelayakan usahatani bunga potong krisan $=\mathrm{R} / \mathrm{C}=\mathrm{Rp}$ $61.350 .000 ; / \operatorname{Rp} \quad 18.220 .711,0=$ 3,37 b. Efisiensi usahatani bunga potong krisan $=\mathrm{B} / \mathrm{C}=\mathrm{Rp}$ 43.129.288,0/Rp $18.220 .711,0=$ 2,367

\section{Analisis Fungsi Produksi Usaha- tani Bunga Potong Krisan}

Untuk menjawab tujuan kedua adalah: Ada 3 uji asumsi yang harus dilakukan sebelum menganalisis faktor- faktor yang mempengaruhi produksi diantaranya uji multikolinearitas, uji autokorelasi dan uji heteroskedastisitas. Berdasarkan penelitian uji asumsi klasik terhadap fungsi produksi cobbdouglass tersebut adalah tidak terjadi hubungan linier diantara variabelvariabel bebasnya (tidak terjadi multikolinearitas), data pengamatan tersebut tidak memiliki autokorelasi, tidak terdapat adanya hubungan yang sistematis antara variabel yang 
menjelaskan dengan nilai mutlak dari residualnya (tidak mengalami heteroskedastisitas).

Hasil analisis faktor faktor potong krisan, pengaruh variabel independen terhadap variabel dependen secara parsial, disajikan pada Tabel 4.

yang mempengaruhi produksi bunga

Tabel 4. Hasil Analisis Faktor-faktor yang Mempengaruhi Produksi Bunga Potong Krisan di Desa Wonosari, Kecamatan Tutur, Kabupaten Pasuruan

\begin{tabular}{llrrrr} 
No & Faktor Produksi & Koefisien & $\mathbf{T}_{\text {hitung }}$ & $\mathbf{T}_{\text {tabel }}$ & Sig \\
& & & & & \\
\hline 1 & Luas lahan & $0.537 * * *$ & 8,895 & 2,042 & .000 \\
2 & Tenaga kerja & 0.005 & 0.131 & & $0.897 \mathrm{~ns}$ \\
3 & Bibit & $0.727 * * *$ & 17.134 & & 0,000 \\
4 & Pupuk kandang & $0.182 * * *$ & 2.847 & & 0.002 \\
5 & Petisida & -0.002 & $-0,136$ & & 0.893 \\
& Konstanta & $1.546 * * *$ & -5.666 & & $.0,000$ \\
\hline & N $=30$ & $\mathrm{R}^{2}=0,998$ & F-hit $=2.853$, & Ftabel $=2.553$
\end{tabular}

Keterangan : $* * *=$ nyata pada $1 \%$

Sumber: Data Primer Diolah (2016)

Hasil analisis menunjukkan bahwa nilai $\mathrm{R}^{2}=0,998$, artinya 99,8 persen produksi usahatani bunga potong krisan ditentukan oleh variabel independen dalam model, sementara itu 0,2 persen ditentukan oleh variabel independen di luar model. Sementara itu nilai $\mathrm{F}$-test $=$ $2,853>$ F-tabel (2,553), menunjukkan bahwa secara bersamasama variable independen dalam model berpengaruh terhadap produksi usahatani bunga potong krisan.
Sementara itu secara parsial variable independent yang berpengaruh terhadap produksi usahatani Bungan potong krisan adalah sebagai berikut.

\section{Variabel Luas Lahan $\left(\mathbf{X}_{1}\right)$}

Luas lahan berpengaruh positif terhadap produksi bunga potong krisan dengan elastisitas $0,537(\alpha=1$ $\%)$. Hasil analisis menunjukan bahwa secara statistik variabel luas lahan berpengaruh positif terhadap produksi usahatani bunga potong krisan dengan nilai koefisien sebesar 
0,537. Artinya jika luas lahan ditambah sebesar $1 \%$ maka produksi meningkat sebesr $0,537 \%$ dan sebaliknya.

\section{Variabel Biaya Pembelian Bibit} $\left(\mathbf{X}_{3}\right)$

Hasil analisis menunjukan bahwa secara statistik variabel bibit berpengaruh positif terhadap produksi dengan koefisien sebesar 0,727, artinya jika bibit ditambah sebesar $1 \%$ maka produksi akan meningkat sebesr $0,727 \%$ dan sebaliknya.

\section{Variabel Biaya Pembelian Pupuk Kandang $\left(\mathbf{X}_{4}\right)$}

Pupuk kandang berpengaruh positif terhadap produksi bunga potong krisan dengan koefisien regresi sebesar 0.182. Artinya apabila pupuk kandang ditambah $1 \%$ maka akan meningkatkan produksi sebesar $0,182 \%$, dan sebaliknya.

\section{KESIMPULAN DAN SARAN}

Berdasarkan hasil penelitian dan pembahasan di atas maka dapat disimpulkan sebagai berikut :

1. Biaya variabel dikeluarkan oleh petani bunga potong krisan adalah sebesar $\quad$ Rp.

18.099.573/ha/musim, biaya tetap Rp. 121.138,70 sedangkan pendapatan Rp. $\quad 43.129 .288$ /ha/musim.

2. Secara bersama-sama variabel luas lahan $\left(X_{1}\right)$, tenaga kerja $\left(\mathrm{X}_{2}\right)$, bibit $\left(\mathrm{X}_{3}\right)$, pupuk kandang $\left(\mathrm{X}_{4}\right)$ dan pestisida $\left(\mathrm{X}_{5}\right)$ berpengaruh terhadap produksi (Y) bunga potong krisan.

3. Secara parsial faktor yang berpengaruh positif terhadap produksi usahatani bunga potong krisan adalah luas lahan $\left(\mathrm{X}_{1}\right)$, bibit $\left(\mathrm{X}_{2}\right)$ dan pupuk kandang $\left(X_{3}\right)$. Sebaliknya variabel tenaga kerja $\left(\mathrm{X}_{2}\right)$ dan pestisida $\left(\mathrm{X}_{5}\right)$ tidak berpengaruh terhadap produksi (Y) bunga potong krisan.

c. Usahatani bunga potong krisan layak untuk dikebangkan, dengan nilai R/C 3.37 yang berarti bahwa setiap Rp1,00 yang digunakan dalam usahatani, akan menghasilkan penerimaan sebesar 3,37. Dari hasil penelitian diperoleh nilai $\mathrm{R} / \mathrm{C}$ adalah $>1$, atau dengan kata lain usahatani ini layak untuk diusahakan. Sementara tu, nilai 
$\mathrm{B} / \mathrm{C}=2,367>1$ yang berarti usahatani bunga potong krisan telah efisien.

Petani di desa Wonosari sebaiknya mencatat semua biayabiaya yang dikeluarkan dalam usahataninya. Sehingga berguna bagi tahun berikutnya atau muitanam berikutnya, supaya dapat mengetahui tingkat keuntungan yang diperoleh secara cepat.

Untuk petani disarankan bahwa penggunaan input produksi perlu diperhatikan karena terdapat input yang berpengaruh negatif terhadap produksi.

Terhadap input yang berpotensi berpengaruh negatif, maka penggunaan input tersebut harus dikurangi. Sebaliknya, input produksi yang menunjukan nilai positif maka ditingkatkan lagi penggunaannya.

\section{DAFTAR PUSTAKA}

Andiani, Y. 2013. Budidaya Bunga Krisan. Pustaka Baru Pres. Yogyakarta.

Wulandari, A. 2008. Analisis Usahatani Tanaman Hias. Disertasi tidak dipublikasikan, Fakultas Pertanian, Universitas Sumatera Utara. Medan.
Rasyid, H. 2005. Analisis Faktorfaktor yang Mempengaruhi Pendapatan Petani.

Sarpintono. 2009. Analisis Efisiensi Penggunaan Faktor-faktor Produksi Usahatani.

Feriady, A. 2013. Analisis Pendapatan dan Faktor-Faktor Yang Mempengaruhi Produksi Usahatni Sawi Pahit.

Wigati, dkk. Analisis Usahatani Bunga Potong Krisan, USM. Surakarta.

Nanang. 2013. Konsep Efisiensi. http://Nanagbudianas.blogspo t.com. Diakses pada tanggal 1 April 2016.

Gujarati, D. 1995. Ekonometrika Dasar. Terjemahan Sumarno Zain. Erlangga. Jakarta.

Wijardono, A. 2005. Ekonometrika Teori dan Aplikasi. Ekonisia. Yogyakarta.

Suryana, S. 2007. Analisis FaktorFaktor Yang Mempengaruhi Produksi Jagung. Semarang. 